\title{
Association between G1733A (rs6152) polymorphism in androgen receptor gene and recurrent spontaneous abortions in Mexican population
}

\author{
Ángela Porras-Dorantes ${ }^{1,2}$ - Aniel Jessica Leticia Brambila-Tapia ${ }^{3}$. \\ Alma Benita Lazcano-Castellanos ${ }^{4}$. Thiago Donizete Da Silva-José ${ }^{1,2}$ • \\ Jesús Alejandro Juárez-Osuna ${ }^{1,2}$ • José Elías García-Ortiz ${ }^{2,4}$
}

Received: 28 April 2017 / Accepted: 28 June 2017 / Published online: 13 July 2017

(C) Springer Science+Business Media, LLC 2017

\begin{abstract}
Introduction Recurrent spontaneous abortion (RSA) is a multifactorial condition that occurs with a frequency of $0.2-5 \%$ in women of reproductive age. Among genetic factors, the single nucleotide polymorphism (SNP) G1733A in the androgen receptor $(A R)$ gene has been associated with its presence in Greek and Iranian populations. Therefore, the aim of this study is to determine its possible association with RSA in this population.

Patients and methods A total of 156 Mexican RSA (with at least 2 consecutive abortions) unrelated patients and 152 unrelated healthy women were included, the presence of karyotype anomalies in the parents as well as uterine anomalies as well as antiphospholipid antibodies was excluded in patients; while all the controls presented at least two healthy pregnancies and no abortion. In all the included women, the presence
\end{abstract}

Aniel Jessica Leticia Brambila-Tapia

anieljessica@hotmail.com

José Elías García-Ortiz

jose.elias.garcia@gmail.com

1 Doctorado en Genética Humana, Universidad de Guadalajara, Guadalajara, Jalisco, Mexico

2 División de Genética, Centro de Investigación Biomédica de Occidente (CIBO), Instituto Mexicano del Seguro Social (IMSS), Sierra Mojada \# 800, Colonia Independencia Oriente, C.P. 44340 Guadalajara, Jalisco, Mexico

3 Departamento de Psicología Básica, Centro Universitario de Ciencias de la Salud (CUCS), Universidad de Guadalajara, Sierra Mojada \#950, Colonia Independencia Oriente, C.P.

44340 Guadalajara, Jalisco, Mexico

4 Dirección de Educación e Investigación en Salud, UMAE Hospital Gineco-obstetricia, CMNO-IMSS, Guadalajara, Jalisco, Mexico of the SNP G1733A was determined by restriction fragment length polymorphism (RFLP) technique.

Results No significant differences were observed in age between groups. The genotype GG, GA, and AA had a frequency of $0.70,0.27$, and 0.03 in controls and of $0.89,0.10$, and 0.01 in patients $(p<0.001)$; while the A allele frequency was of 0.06 and 0.16 in controls and patients, respectively $(p<0.0001)$. The difference in allele frequency increased $10-15 \%$ when patients with primary RSA (with no live births) and with at least three abortions were included.

Conclusions The SNP G1733A of the AR gene is significantly associated with RSA in Mexican patients. These results coincide with previous reports in other populations.

Keywords Recurrent spontaneous abortion - Androgen receptor gene $\cdot$ G1733A polymorphism

\section{Introduction}

Recurrent spontaneous abortion (RSA) is a condition in women of reproductive age defined as three or more consecutive pregnancy losses before the 20th week of gestation and has been documented with a frequency of $0.5-2 \%$ [1]. However, some authors consider it two pregnancies loses [2], a condition that presents a frequency of 5\% [3]. The RSA can be primary or secondary depending whether the couple has had a live birth previously (secondary) or not (primary) [3]. The presence of RSA remains unexplained in around 45-50\% of patients $[4,5]$. Regarding the main causes, it has been shown that the frequency of cytogenetic abnormalities in miscarriage tissues obtained from women with RSA is higher than in general population, although it is lower than in women with sporadic loss (25-50\% versus 50-70\%) [6, 7], and the frequency 
of parental karyotyping abnormalities including balanced translocations is also higher in couples with history of RSA than in the general population (2-5 versus $0.2 \%$ ) [8].

With respect to other causes, it has been proven that genetic, pathophysiologic, and environmental factors are associated with RSA; among the non-genetic factors are the uterine anatomic abnormalities, endocrine abnormalities, obesity, sperm quality, and parental age [8]. In addition, many mutations and polymorphisms in different genes have been associated with RSA, these have been reported in genes coding for cytokines, proteins related with blood coagulation (prothrombin and factor V Leiden), sex hormone receptors, and others (VEGF, MTHFR, p53) [9]; the X chromosome skewed inactivation $(>90 \%)$ has also reported as a risk factor for RSA [10].

Among the sex hormone receptors, the androgen receptor $(A R)$ gene (located between Xq11-q12), codes for a protein that functions as a nuclear transcription factor activated by a steroid hormone, and the single nucleotide polymorphism (SNP) (G1733A/rs6152) has been associated with RSA in Iranian and Greek populations [2, 11]; however, considering that this polymorphism has been studied in very few pathologies including RSA and no studies have been conducted in Mexican population, we decided to determine if its presence was associated with RSA in this population.

\section{Patients and methods}

\section{Patients}

A total of 156 unrelated women with primary and secondary RSA were included, the inclusion criteria were: Mexican women (from the West side) from 18 to 42 years of age with at least two consecutive pregnancy losses with the same partner before the 20th week of gestation, normal karyotype in the couple, normal hysterosalpingography, negative antiphospholipids antibodies, and without the diagnosis of polycystic ovary and diabetes.

The control group was formed of 152 unrelated healthy women from the West side of Mexico, with at least two live births, without history of abortions, and by interview, they denied the presence of uterine malformations, antiphospholipid syndrome, and polycystic ovary. All patients and controls signed an informed consent.

\section{Methods}

DNA was extracted from peripheral blood leukocytes by the salting-out method [12], and the DNA amplification was performed with the following primers: forward primer 5CTGGATGAGGAACAGCAACC-3 and reverse primer 5CGTTGTCAGAAATGGTCGAA-3' [11]; the polymerase chain reaction (PCR) was performed with 35 cycles, each cycle containing denaturation at $94{ }^{\circ} \mathrm{C}$ for $25 \mathrm{~s}$, annealing at $64{ }^{\circ} \mathrm{C}$ for $25 \mathrm{~s}$, and extension at $72{ }^{\circ} \mathrm{C}$ for $90 \mathrm{~s}$, with a final extension time of $4 \mathrm{~min}$ at $72^{\circ} \mathrm{C}$. The final product of $379 \mathrm{bp}$ was posteriorly digested with the restriction enzyme StuI at $37{ }^{\circ} \mathrm{C}$ for $30 \mathrm{~min}$ and inactivated at $75{ }^{\circ} \mathrm{C}$ for $5 \mathrm{~min}$. The mutated allele (A variant) produced a complete fragment of $379 \mathrm{bp}$, while the wild type allele ( $\mathrm{G}$ variant) produced a fragment of $313 \mathrm{bp}$. The fragments were separated on $6 \%$ acrylamide gel stained with silver nitrate.

\section{Statistical analysis}

The descriptive statistics consisted in frequencies and percentages for the allele and genotype frequencies and of means and standard deviations for the quantitative variables (women age, number of abortions/pregnancies/deliveries). The comparison of the allele and genotype frequencies between the patients and controls was performed with chi-square and Fisher's exact tests and in the case of the allele frequencies, the odds ratio was also calculated. For the quantitative variables we used Student $T$ test for independent samples, with a $p$ value $<0.05$ considered as statistically significant for all probes. The statistical analyses were performed in SPSS version 10.0.

\section{Results}

The mean age of the patients was $32.16 \pm 4.85(18-43)$ years and of the controls was $28.88 \pm 5.29(18-43)$ years $(p>0.05)$; the number of pregnancies, normal deliveries, cesarean sections, and abortions in both groups are described in Table 1. The allele and genotype frequencies between patients and controls showed significant differences (Table 2), being the A allele (mutant) $10 \%$ more frequent in patients with RSA than in controls $(p<0.0001)$. The differences among the genotypes also showed statistical significance $(p<0.001)$, being the homozygous (AA) and the heterozygous (GA) more frequent in patients. If we analyze only the cases with three or more abortions $(N=107)$, slight changes are observed with an increase in the difference of the frequency of the A allele between patients and controls from 10 to $12 \%(p<0.0001)$.

Table 1 Pregnancy history in patients and controls

\begin{tabular}{llll}
\hline & Patients $(N=156)$ & Controls $(N=152)$ & $P$ value \\
\hline Pregnancies & $3.64 \pm 1.16(2-6)$ & $2.41 \pm 0.93(1-4)$ & $<0.0001$ \\
Normal deliveries & $0.31 \pm 0.65(0-3)$ & $1.68 \pm 1.17(0-4)$ & $<0.0001$ \\
Cesarean sections & $0.31 \pm 0.577(0-3)$ & $0.74 \pm 0.88(0-3)$ & $<0.0001$ \\
Abortions & $2.96 \pm 0.87(2-6)$ & $0 \pm 0(0-0)$ & $<0.0001$ \\
\hline
\end{tabular}

Data is described in means $\pm \mathrm{SD}$ (ranges), $P$ value obtained with $T$ test for independent samples 
Table 2 Allele and genotype distribution between patients and controls

\begin{tabular}{lllll}
\hline $\begin{array}{l}\text { Genotype/allele } \\
\mathrm{N}(\%)\end{array}$ & $\begin{array}{l}\text { Patients N }(\%) \\
(N=156)\end{array}$ & $\begin{array}{l}\text { Controls N }(\%) \\
(N=152)\end{array}$ & OR (95\% CI) & $<0.001$ \\
\hline $\mathrm{GG}$ & $110(70.51)$ & $135(88.82)$ & \\
$\mathrm{GA}$ & $42(26.92)$ & $16(10.53)$ & & \\
AA & $4(2.57)$ & $1(0.65)$ & $3.03(1.67-5.55)$ & $<0.0001$ \\
Allele & & & & \\
A & $50(16)$ & $18(6)$ & & \\
G & $262(84)$ & $286(94)$ & & \\
\hline
\end{tabular}

Data showing the number and percentages of allele and genotype frequencies in patients and controls. In the third column, it is described the OR with the interval coefficient of $95 \%$ for the comparison of allele frequencies
A similar change is observed when we only include patients without any live birth $(N=80)$ with a difference in the A allele frequency of $11.5 \%(p<0.0001)$, and when we combine both characteristics $(\geq 3$ abortions and no live births) $(N=54)$, the difference increases to $15 \%(p<0.00001)$. In contrast, this difference is reduced to $5 \%$, being no significant) when we only analyze the patients with $\leq 2$ abortions $(N=49, p=0.07)$. The genotypic frequencies in patients and controls did not deviate from the Hardy-Weinberg equilibrium $(p>0.05)$.

\section{Discussion}

The prognosis of RSA has been reported favorable with a likelihood of live subsequent births around 50-80\% [3]; however, each case is different and many factors contribute to the success in future pregnancies, like the cause of the RSA (if known), maternal age, the number of preceding looses and the presence of heart beat in 2-3 of the first three miscarriages presented [13].

In this study, we observed a significant association between the A allele of the G1733A SNP and RSA, results that coincide with the previous reports in Iranian and Greek populations $[2,11]$; however in this report, the difference in the $\mathrm{A}$ allele frequency between patients and controls was lower than in the previous reports from Jahaninejad et al. and Karvela et al. (10\% versus $37 \%$ and $14 \%$, respectively). This difference can be attributed to the patient selection criteria, because in the previous reports only patients without a live birth were included, and in the case of the study of Karvela et al., patients with at least three abortions were included. When we used these criteria, a difference of $15 \%$ in the frequency of the A allele between patients and controls is observed, which is $1 \%$ higher than that found by Karvela et al. This differences suggest that the A allele can be more associated with primary RSA with more than three abortions. It is also important to consider that the allelic frequencies in controls were different in Mexican population, in which the A allele frequency was higher than in the previous reports (0.94 versus 0.84$)$, which could also influence the associations observed in the different populations.
In this regard, taking into account that the G1733A SNP was also associated with RSA in a different population (Mexican) from the previously studied (Greek and Iranian), we consider that this SNP begins to be of interest for further research in other populations.

The G1733A polymorphism is a silent SNP that does not produce an amino acid change at the position 211 of the protein, which is the glutamic acid; however, it has been shown that some silent SNP's have a functional effect by modifying the co-translational folding and thus the tridimensional structure of the protein [14]. On the other hand, the G1733A SNP is located in exon 1 between 2 polymorphic trinucelotide repeats (CAG and GGC) that code for polyglutamine and polyglicine tracts [11], and in vitro studies have shown that these variants are related with $A R$ gene activity $[15,16]$; in addition, the codon 211 resides in the $\mathrm{N}$-terminal domain of the $A R$ gene, that harbors the major transcription activation functions [17]. Therefore, a possible link between G1733A SNP and functional and/or transcriptional effects can be related with linkage disequilibrium with other variants or can be driven by unknown mechanisms associated with its important position in the gene.

The lack and excess of circulating androgens in premature ovarian failure and polycystic ovary syndrome, respectively, are associated with increased risk to early fetal loss and late obstetric complications due to impaired placental function [18-20]. In addition, it has been shown that increased responsiveness to androgen signaling is associated with decidualization of human endometrial stromal cells through cytoskeletal organization and cell cycle regulation, functions that may be critical for trophoblast invasion and placental development [21]. Therefore, a change in AR activation and/or expression through genetic variants, including the G1733A SNP, could lead to modifications in the endometrium that increase the likelihood of miscarriage.

In conclusion, we observed a significant association between the A allele of the SNP G1733A and RSA in the allele and genotype frequencies, being higher when only patients with at least three abortions and without a live birth are included. These results coincide with the two previous reports that searched for this association, which suggests that this SNP 
is a risk factor to develop RSA in different populations. However, considering that this SNP is silent, further experimental studies will determine its effects in the androgen receptor function and/or expression.

\section{Compliance with ethical standards}

Ethical approval The project was approved by the ethics committee of the Mexican Institute of Social Security with the number: R-2010-13053 , and all patients signed an informed consent prior to be included in the study.

\section{References}

1. Wilcox AJ, Weinberg CR, O'Connor JF, Baird DD, Schlatterer JP, Canfield RE, et al. Incidence of early loss of pregnancy. N Engl J Med. 1988;319:189-94.

2. Jahaninejad T, Ghasemi N, Kalantar SM, Sheikhha MH, Pashaiefar $\mathrm{H}$. StuI polymorphism on the androgen receptor gene is associated with recurrent spontaneous abortion.J Assist Reprod Genet. 2013; 30: $437-40$.

3. Shahine L, Lathi R. Recurrent pregnancy loss: evaluation and treatment. Obstet Gynecol Clin N Am. 2015;42:117-34.

4. Stephenson MD. Frequency of factors associated with habitual abortion in 197 couples. Fertil Steril. 1996;66:24-9.

5. Stephenson M, Kutteh W. Evaluation and management of recurrent early pregnancy loss. Clin Obstet Gynecol. 2007;50:132-45.

6. Stephenson MD, Awartani KA, Robinson WP. Cytogenetic analysis of miscarriages from couples with recurrent miscarriage: a casecontrol study. Hum Reprod. 2002;17:446-51.

7. Carp HJ. Recurrent miscarriage: genetic factors and assessment of the embryo. Isr Med Assoc J. 2008;10:229-31.

8. Hyde KJ, Schust DJ. Genetic considerations in recurrent pregnancy loss. Cold Spring Harb Perspect Med. 2015;5:a023119.

9. Daher S, Torloni MR, Gueuvoghlanian-Silva BY, Moron AF, Mattar R. Inflammatory mediator gene polymorphisms and gestational diabetes: a review of the literature. J Reprod Immunol. 2011;90:111-6.
10. Su MT, Lin SH, Chen YC. Association of sex hormone receptor gene polymorphisms with recurrent pregnancy loss: a systematic review and meta-analysis. Fertil Steril. 2011;96:1435-44. e1

11. Karvela M, Stefanakis N, Papadopoulou S, Tsitilou SG, Tsilivakos V, Lamnissou K. Evidence for association of the G1733A polymorphism of the androgen receptor gene with recurrent spontaneous abortions. Fertil Steril. 2008;90:e9-12.

12. Miller SA, Dykes DD, Polesky HF. A simple salting out procedure for extracting DNA from human nucleated cells. Nucleic Acids Res. 1988;16(3):1215.

13. Kling C, Magez J, Hedderich J, von Otte S, Kabelitz D. Two-year outcome after recurrent first trimester miscarriages: prognostic value of the past obstetric history. Arch Gynecol Obstet. 2016;293(5): 1113-23.

14. Kimchi-Sarfaty C, Oh JM, Kim IW, Sauna ZE, Calcagno AM, Ambudkar SV, et al. A "silent" polymorphism in the MDR1 gene changes substrate specificity. Science. 2007;26(315):525-8.

15. Chamberlain NL, Driver ED, Miesfeld RL. The length and location of CAG trinucleotide repeats in the androgen receptor $\mathrm{N}$-terminal domain affect transactivation function. Nucleic Acids Res. 1994;22:3181-6.

16. Ding D, Xu L, Menon M, Reddy GP, Barrack ER. Effect of GGC (glycine) repeat length polymorphism in the human androgen receptor on androgen action. Prostate. 2005;62:133-9.

17. Grad JM, Lyons LS, Robins DM, Burnstein KL. The androgen receptor (AR) amino-terminus imposes androgen-specific regulation of AR gene expression via an exonic enhancer. Endocrinology. 2001;142:1107-16.

18. Abdalla HI, Billett A, Kan AK, Baig S, Wren M, Korea L, et al. Obstetric outcome in 232 ovum donation pregnancies. Br J Obstet Gynaecol. 1998;105:332-7.

19. Castracane VD, Asch RH. Testosterone and androstenedione in premature ovarian failure pregnancies: evidence for an ovarian source of androgens in early pregnancy. Hum Reprod. 1995;10: $677-80$.

20. de Vries MJ, Dekker GA, Schoemaker J. Higher risk of preeclampsia in the polycystic ovary syndrome. A case control study. Eur J Obstet Gynecol Reprod Biol. 1998;76:91-5.

21. Cloke B, Huhtinen K, Fusi L, Kajihara T, Yliheikkilä M, Ho KK, et al. The androgen and progesterone receptors regulate distinct gene networks and cellular functions in decidualizing endometrium. Endocrinology. 2008;149:4462-74. 